\title{
A Análise da Carga Tributária na Atual Conjuntura Econômica Brasileira na Indústria de Transformação
}

\author{
Clislânio da Silva Correia ${ }^{1}$; Daiana Ferreira de Alencar Diógenes ${ }^{2}$
}

\begin{abstract}
Resumo: Este trabalho teve como objetivo analisar a carga tributária sobre a indústria de transformação na atual economia brasileira a fim de avaliar se a referida carga tributária interfere no desenvolvimento econômico deste ramo da indústria. Já especificamente visou: compreender o que é, e o que caracteriza o tributo na atual legislação brasileira, investigar a tributação existente na atualidade sobre uma indústria de transformação, e o que é desenvolvimento econômico. Trata-se de um Estudo de Caso, que utilizou como recurso para a coleta de dados uma entrevista estruturada, com perguntas que comtemplassem os objetivos a serem alcançados. O presente trabalho transcorreu de agosto a novembro, sendo a pesquisa de campo realizada em outubro, na empresa de transformação, que já está no mercado atuando a oito anos produzindo sucos e temperos culinários, está localizada na cidade de Icó- Ceará. Destaca-se que devido à grande carga tributária, muitas empresas brasileiras não estão conseguindo desenvolver-se de forma mais rápida, e muita das vezes estão preferindo mudar de pais, uma vez que devido ao seu aumento, os produtos consequentemente também iram aumentar o preço, além de todos os tributos que são aplicados nessas empresas.
\end{abstract}

Palavras-chave: Carga Tributária. Desenvolvimento Econômico. Indústria de Transformação.

\section{The Analysis of the Tax Burden in the Current Brazilian Economic Environment in the Transformation Industry}

Abstract: The objective of this study was to analyze the tax burden on the manufacturing industry in the current Brazilian economy in order to assess whether the tax burden interferes with the economic development of this branch of industry. Specifically, it aimed to: understand what is and what characterizes the tribute in the current Brazilian legislation, investigate the current taxation on a manufacturing industry, and what is economic development. It is a Case Study, which used as a resource for the data collection a structured interview, with questions that contemplate the objectives to be achieved. This work was carried out from August to November. The field research was carried out in October, at the transformation company, which is already in the market for eight years producing juices and culinary seasonings, located in the city of Icó-Ceará. It should be noted that due to the large tax burden, many Brazilian companies are not able to develop faster, and often are preferring to change their parents, since due to their increase, the products consequently also increase the price, in addition to all taxes that are applied in these companies.

Key worlds: Tax Burden. Economic development. Transformation industry.

\footnotetext{
${ }^{1}$ Discente do curso de Ciências Contábeis da Faculdade Vale do Salgado (FVS). E-mail: clislan_25@ outlook.com;

${ }^{2}$ Especialista em Metodologia da Docência do Ensino Superior pela Faculdade Vale do Salgado (FVS), e em Direito do Trabalho e Previdenciário pela Universidade Regional do Cariri (URCA), Professora do curso de Ciências Contábeis da Faculdade Vale do Salgado. E-mail: daianaferreira@fvs.edu.br
}

Id on Line Rev. Mult. Psic. V.13, N. 43, p. 530-542, 2019 - ISSN
Edição eletrônica em http://idonline.emnuvens.com.br/id 


\section{Introdução}

No atual cenário econômico, com toda a evolução tecnológica, se é exigido das empresas e dos seus funcionários, uma minimização dos custos e despesas, uma vez que as mesmas enfrentam uma enorme dificuldade em relação ao complexo sistema econômico, sua constante mudança de legislação tributária e suas altas cargas, fazendo com que as empresas busquem novas estratégias para otimizar os gastos tributários.

Com isso, se tornou imprescindível se realizar uma minuciosa análise sobre todos os regimes tributários, planejar se tornou crucial, principalmente no Brasil, onde as cargas tributárias concebem um grande montante financeiro, interferindo assim diretamente no resultado econômico das empresas, possuindo como melhor proposta o planejamento tributário.

De acordo com Sabbag (2014) os tributos é a maneira do estado de arrecadar receita derivada do patrimônio dos indivíduos, que está fundamentado no seu poder de tributar, portanto, resulta numa exigência do Estado, identificada na lei, e hoje como a expressão da vontade coletiva, para resolver as questões sociais da sociedade, como educação, saúde, infraestrutura, visando à melhoria de todos.

O Código Tributário Nacional (CNT), em seu artigo $3^{\circ}$, define tributo como "toda prestação pecuniária compulsória, em moeda ou cujo valor nela se possa exprimir, que não constitua sanção de ato ilícito, instituída em lei e cobrada mediante atividade administrativa plenamente vinculada". Todo tributo tem uma norma que determina como será seu processo de cobrança, devendo a lei ser obedecida integralmente para não ocorrer prejuízo para toda sociedade (BRASIL, 2012).

Observando todos os processos em que uma empresa passa para poder estabilizar-se no comércio, se fez pertinente o tema desse estudo, que tem como objetivo analisar a carga tributária sobre a indústria de transformação na atual economia brasileira a fim de avaliar se a referida carga tributária interfere no desenvolvimento econômico deste ramo da indústria, de suma importância para desenvolvimento econômico do País.

E para que se atinja a meta estabelecida, é preciso observar outros objetivos secundários propostos, como: Compreender o que é, e o que caracteriza o tributo na atual legislação brasileira, investigar a tributação existente na atualidade sobre uma indústria de transformação, e o que é desenvolvimento econômico.

Para a estruturação desse trabalho, iniciou-se com uma pesquisa bibliográfica, analisando livros, periódicos, revistas e textos que abordam a questão tributária, o planejamento e a minimização de cargas tributárias nas empresas. A pesquisa se complementará com um 
estudo de caso, identificando através de documentos comprobatórios e entrevista a ocorrência dos fatos, possibilitando assim elaborar sugestões acerca da situação atual e da projeção frente às possibilidades de enquadramento tributário.

\title{
Fundamentação Teórica
}

\section{Espécies de tributos - impostos, taxas e contribuições de melhorias}

Art. 16 o CTN (2012) traz o conceito de imposto para diferenciar dos outros tributos: "Imposto é o tributo cuja obrigação tem por fato gerador uma situação independente de qualquer atividade, estatal específica, relativa ao contribuinte".

Borba (2015) cita que o imposto pode ser considerado por excelência, não apenas por representar as cincos espécies, mas por ter uma individualidade principal a simples condição de transferir de forma compulsória, os recursos da sociedade para os cofres públicos à parti do fato previsto em lei. Os exemplos de imposto são: Imposto sobre produtos industrializado (IPI), imposto sobre serviço de qualquer natureza (ISS).

Diferentemente dos impostos, o fato gerador das taxas é uma atividade que o poder público realiza para o contribuinte e para custear tais atividades, são instituídas as taxas.

O CTN em seu art. 77 traz o conceito de taxa:

\begin{abstract}
As taxas cobradas pela União, pelos Estados, pelo Distrito Federal ou pelos Municípios, no âmbito de suas respectivas atribuições, têm como fato gerador o exercício regular do poder de polícia, ou a utilização, efetiva ou potencial, de serviço público específico e divisível, prestado ao contribuinte ou posto à sua disposição. (CTN, 2012, p. 62).
\end{abstract}

Segundo Sabbag (2014) o fator gerador da taxa é cobrado devido à respectiva prestação de serviço estatal a comunidade, sendo cobrado ao beneficiário da prestação de serviços, por essa razão os tributos podem ser vinculados a atuação do estado, sendo de competência da união, dos estados e municípios, os exemplos de taxa: taxa de coleta de lixo, taxa de licença e funcionamento.

As contribuições de melhorias são tributos que surgem com a realização de uma obra pública da qual decorra valorização imobiliária aos contribuintes. Tendo como maior motivação o impedimento de que um determinado número de pessoas possua um enriquecimento as, custas, da coletividade. Já havia sido prevista em outras constituições, anteriores a atual, não sendo, portanto, qualquer novidade a sua previsão no tex to constitucional de 1988. 
Segundo Sabbag (2014) contribuição de melhoria é um "tributo especial”, pois não se confunde com taxa nem com imposto, pois se pressupõe a uma obra pública, que traz valorização do bem imóvel, assim com o imposto por sua vez, não se confunde, uma vez que, se distingue porque depende de atividade estatal.

\section{Carga tributária sobre a indústria de transformação}

Segundo a Firjan (2016) a carga tributária brasileira está equiparada a de países desenvolvidos, sendo superior a muitos países emergentes. Tendo em vista que o setor com a maior carga tributária é o da industrial que em, 2015, correspondia 47,4\% de toda sua produção, ou seja, quase a metade tudo que é produzido é para pagar impostos. Esse mesmo setor é responsável por $17,2 \%$ do Produto Interno Pronto do país.

Em 2014, a indústria de transformação foi responsável por $30 \%$ de toda arrecadação de impostos no país, tendo em vista que esse setor é um dos que mais geram empregos direto e indireto, em todos os estados brasileiros, dessa forma os custos dos produtos, se tornam altos se tonando inviável a concorrência com produtos internacionais, já que $38 \%$ do que se compra em produtos industrializados é de imposto (FIESP 2015).

Se no setor produtivo brasileiro houvesse um estimulo na aplicação da produção, um ambiente favorável para os negócios, atraísse novos investimentos, com preços mais acessíveis o seu potencial seria muito mais elevado, fazendo assim com que a grande evasão das empresas diminuísse (VEDANA, 2017).

O brasileiro trabalha quase cinco meses por ano para pagar tributos e isso é considerado muito imposto, e muitas das vezes não percebem, e não veem o retorno nos serviços públicos, tendo em vista que muitos são obrigados a pagar do próprio bolso por serviços de educação, saúde e segurança (CAMPGNOLO, 2011)

Segundo Campagnolo (2011), A carga tributária hoje está em quase 40\% do Produto Interno Bruto do País e o brasileiro está no limite do que pode pagar em impostos. E ao contrário do que muitos pensam, todos somos, consumidores, quando requeremos um serviço, ou quando compramos algo esses impostos são repassados para os consumidores na grande maioria.

Segundo Bacha (2013) a crise econômica junto com a alta carca tributária tem sido uns dos fatores que acarretam o fechamento de muitas indústrias no Brasil, ou evasão para outros países que possam dar segurança governamental, e tributária para que essas empresas possam crescer, alinhado a isso o país tem perdido milhões de postos de trabalho. 


\section{Desenvolvimento econômico}

Para Borbely (2016) o conceito de desenvolvimento econômico tem que está conectado, com o bem-estar, a melhoria na qualidade de vida da sociedade, na eficácia das instituições e principalmente na estrutura produtiva do País.

Para Lanzana (2009) o crescimento econômico, é a meta mais importante a ser perseguida pelos formuladores da política econômica, visando à busca do aumento da produtividade industrial, de serviços e mercadorias. Assim a renda per capita familiar tente crescer juntamente com o consumo, tornando uma cascata de crescimento.

A transformação econômica de um país, ela passa pelo desenvolvimento econômico de seu povo, ou seja, uma distribuição de renda, com empregos, educação, saúde, infraestrutura, estimulando a capacidade de empreender para haver o número maior de pessoas com uma renda per capita melhor.

O desenvolvimento econômico é um processo histórico de acumulação de capital e, um aumento na produtividade, elevando o crescimento de um país e, à melhoria dos padrões de vida da população, buscando melhorar o quadro social dos indivíduos (PEREIRA, 2006).

Como foi relatado mais em cima o estudo das ciências econômicas é divido em períodos ao qual cada período com seus respectivos pensadores, que consequentemente formularam suas teorias baseadas na realidade vivida em cada período, ou seja, essas teorias tiveram grande influência do seu período histórico e dos acontecimentos presenciados.

De acordo com Bruno (2017), no Brasil além de uma reforma tributária é necessário que aja incentivos fiscais, em determinadas regiões, para que se tenha um desenvolvimento descentralizado dos grandes centros do país, em especial o Sul e Sudeste. Assim diminuindo os crescentes números da violência que assolam famílias por falta emprego.

\section{Planejamento tributário no Brasil}

Planejar é a condição básica para execução de qualquer trabalho, para a obtenção de maior lucratividade e não se pode negar que devido a todos os tributos que o consumidor e as empresas tem que pagar, o contribuinte tenha por direito organizar os seus negócios de forma que haja um melhor rendimento, e o poder jurídico por sua vez não intervém nesta organização, exceto quando interfere em questões de direito público. 
Sendo assim o planejamento tributário, é um conjunto de sistemas legais que tem como função diminuir o pagamento de tributos, onde o contribuinte organiza seus negócios da melhor forma e tem como elemento principal, ser formado por atos lícitos. Como Fabretti (2006, p.32), vem para confirmar que planejamento tributário é: "O estudo feito preventivamente, ou seja, antes da realização do fato administrativo, pesquisando-se seus efeitos jurídicos e econômicos e as alternativas legais menos onerosas, que exige antes de tudo, bom senso do planejador".

Se a empresa resolve diminuir seus encargos, ela pode recorrer as maneira legais, sendo essa chamada de elisão fiscal ou economia legal, e a forma ilegal sendo denominada de evasão fiscal e é preciso se ter em mente de que planejamento tributário jamais deve ser confundido com sonegação fiscal, uma vez que planejar é escolher entre as melhores opções licitas, e sonegar, é fazer uso de meios ilegais para deixar de recolher os devidos tributos (SANTOS; OLIVEIRA, 2007).

Conforme Fabretti (2001) podem ser utilizadas três tipos de Planejamento Tributário:

a) Planejamento que tem por objetivo a anulação do ônus fiscal;

b) Planejamento que tem por objetivo a redução do ônus fiscal, ou reduzir a base de cálculo do tributo;

c) Planejamento que tem por objetivo o adiamento do ônus fiscal, sem o acontecimento de uma multa, somente com o um planejamento adequado do fluxo de caixa.

De acordo com a Secretaria da Receita Federal (Brasil, 2007), o Sistema Integrado de Pagamento de Impostos e Contribuições das Microempresas e Empresas de Pequeno Porte (SIMPLES) é um regime de arrecadação, cobrança e fiscalização de tributos previsto na Lei Complementar $n^{\circ} 123$, de 14.12.2006, aplicável às Microempresas e às Empresas de Pequeno Porte. O SN entrou em vigor em $1^{\circ}$ de julho de 2007, em substituição ao Simples Federal, ou Simples, criado pela Lei no 9.317, de 1996.

\footnotetext{
Art. 13. O Simples Nacional implica o recolhimento mensal, mediante documento único de arrecadação, dos seguintes impostos e contribuições:

I - Imposto sobre Renda da Pessoa Jurídica - IRPJ;

II - Imposto sobre Produtos Industrializados - IPI;

III - Contribuição Social sobre Lucro Líquido - CSLL;

IV - Contribuição para Financiamento da Seguridade Social - COFINS;

V - Contribuição para o PIS/PASEP;

VI - Contribuição Patronal Previdenciária - CPP;

VII - Imposto sobre Operações Relativas à Circulação de Mercadorias e Sobre Prestações de Serviços de Transporte Interestadual e Intermunicipal e de Comunicação - ICMS;

VIII - Imposto sobre Serviços de Qualquer Natureza - ISS
}

O Lucro Presumido é um tipo de regime tributário, o montante a ser tributado é determinado com base na receita bruta, através da aplicação de alíquotas variáveis em função 
da atividade geradora da receita. Podem optar pelo lucro presumido as pessoas jurídicas, cuja receita bruta total no ano-calendário anterior tenha sido igual ou inferior a $\mathrm{R} \$ 48.000 .000,00$ ou ao limite proporcional de $\mathrm{R} \$ 4.000 .000,00$ multiplicados pelo número de meses de atividade no ano, se esse for inferior a 12 meses. No regime do lucro presumido são quatro os tipos de impostos federais incidentes sobre o faturamento, dentre eles o PIS e a COFINS, que devem ser apurados mensalmente, e o IRPJ e a CSLL cuja apuração deverá ser feita trimestralmente (RICHATO, 2010).

O Lucro Presumido é uma modalidade optativa de apurar o lucro e, consequentemente, o imposto de renda das pessoas jurídicas que, partindo dos valores globais da receita, presumese o lucro a ser tributado (NEVES; VICECONTI, 2007), podemos dizer que é uma presunção por parte do fisco, do que seria o lucro de uma empresa caso não existisse a contabilidade.

Lucro real é a forma de tributação completa, pode se dizer que é aquele realmente apurado pela contabilidade, com base na escrituração comercial e fiscal apurada trimestralmente, ou anualmente. "Lucro Real é o lucro líquido do período, apurado com observância das normas das legislações comercial e societária, ajustado pelas adições, exclusões ou compensações prescritas pela legislação do Imposto de Renda." (SILVA, 2006, p.01).

Estão obrigadas a optar pela tributação com base no Lucro Real as pessoas jurídicas que estiverem enquadradas nas seguintes condições:

\footnotetext{
I - Que tenham receita total, no ano-calendário anterior, superior a $\mathrm{R} \$ 48.000 .000,00$, ou proporcional ao número de meses do período, quando inferior a 12 meses;

II - Cujas atividades sejam de bancos comerciais, bancos de investimentos, bancos de desenvolvimento, caixas econômicas, sociedades de crédito, financiamento e investimento, sociedade de credito imobiliário, sociedades de corretores de títulos, empresas de seguros, empresas de arrendamento mercantil, cooperativas de crédito e entidades de previdência privada aberta;

III - Que tiverem lucros, rendimentos, ou ganhos de capital oriundo do exterior;

IV - Que, autorizadas pela legislação tributária, usufruam de benefícios fiscais relativos á isenção ou redução do imposto;

$\mathrm{V}$ - Que, no decorrer do ano-calendário, tenham efetuado pagamento mensal pelo regime de estimativa, na forma do art. 222;

VI - Que, cuja a atividade seja de factoring.

VII - Que explorem as atividades de securitização de créditos imobiliários, financeiros e agronegócio.
}

\section{Metodologia}

O estudo foi realizado junto ao empresário, para obter-se, dados consistentes. A empresa está localizado no município de Icó - CE, na Rodovia CE - Tarcísio Monteiro, 1000, 
no Conjunto Gama, sendo a mesma o objeto de estudo uma indústria de transformação de produtos alimentícios, sendo assim aplicado um questionário com 07 questões abertas para o proprietário da empresa, no mês de novembro de 2018, perguntas estas que buscaram concretizar os objetivos da presente pesquisa, tendo assim como objetivo principal analisar a carga tributária sobre a indústria de transformação na atual economia brasileira a fim de avaliar se a referida carga tributária interfere no desenvolvimento econômico deste ramo da indústria tendo ainda como objetivos específicos: compreender o que é, e o que caracteriza o tributo na atual legislação brasileira, investigar a tributação existente na atualidade sobre uma indústria de transformação, e o que é desenvolvimento econômico. O presente trabalho transcorreu de agosto a outubro de 2018 e se enquadra na condição de um Estudo de Caso

Para o desenvolvimento desse artigo será realizado inicialmente uma pesquisa bibliográfica, que segundo Gil (2010), é desenvolvida com vários materiais já elaborado, disponíveis de diversas formas, podendo ser em livros, artigos científicos e teses. Uma revisão bibliográfica oferece um avanço no campo do conhecimento, pois sempre é necessário inicialmente conhecer o que já está sendo realizado por outros pesquisadores.

E para que a pesquisa tenha um maior enriquecimento de dados, foi optado por realizar um estudo de caso, que para Goode e Hatt (1979), o estudo de caso é um meio de organizar os dados, preservando do objeto estudado o seu caráter unitário, considera a unidade como um todo, incluindo o seu desenvolvimento.

E ainda segundo Gomes (2008) "exige do investigador, o emprego de alguns procedimentos metodológicos, como protocolo do estudo; preparação prévia para o trabalho de campo; estabelecimento de base de dados etc." E como forma de coletar os dados da pesquisa, será utilizado uma entrevista que de acordo com Haguette $(1997$, p. 86) é um "processo de interação social entre duas pessoas na qual uma delas, o entrevistador, tem por objetivo a obtenção de informações por parte do outro, o entrevistado".

\section{Resultados e Discussões}

No que diz respeito à aplicação do questionário, foi aplicado em relação a um empresário da indústria de transformação, sediado na cidade de Icó - CE, com oito anos de atuação no mercado, mais precisamente, na fabricação de sucos, dispondo atualmente de dois galpões, um destinado para temperos culinários, e outro destinado para sucos. O questionário conta com 7 perguntas, destinadas à identificação do empresário entrevistado e à resolução do 
problema proposto na presente pesquisa. Inicialmente, foi investigado o período de atuação e o atual faturamento da empresa, ao que o empresário entrevistado respondeu que:

\footnotetext{
“A empresa tem oito anos de atuação no mercado na fabricação de sucos, e hoje conta com um galpão para fabricar colorau $e$ outro para fabricar sucos $e$ achocolatado".

"Atualmente o faturamento anual da empresa é 3.600.000,00 mil Reais".
}

Em seguida, investigou-se a quantidade de impostos que esta empresa paga anualmente, e qual o regime tributário é utilizado, tendo como resposta:

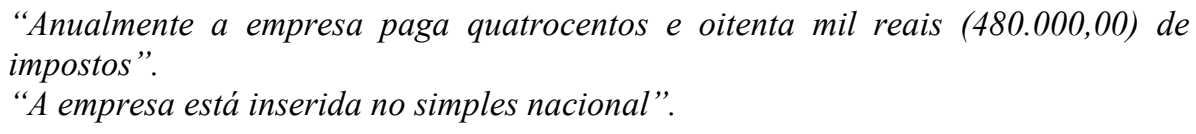

De acordo com a Secretaria da Receita Federal (Brasil, 2007), o Sistema Integrado de Pagamento de Impostos e Contribuições das Microempresas e Empresas de Pequeno Porte (SIMPLES) é um regime de arrecadação, cobrança e fiscalização de tributos previsto na Lei Complementar nº 123, de 14.12.2006, aplicável às Microempresas e às Empresas de Pequeno Porte.

O Simples Nacional é um regime de tributação unificado, ou seja, reúne diferentes tributos, da competência da União, dos Estados e dos Municípios em uma única guia, o que facilita a arrecadação das empresas de pequeno porte.

Atualmente os impostos representam 13,33\% do faturamento anual da empresa, uma margem que poderia está sendo usada para ampliação e a capacidade produtiva, gerando empregos e renda para as famílias residentes na cidade.

Segundo Pereira (2006) o desenvolvimento econômico é um processo histórico de acumulação de capital, e, um aumento na produtividade, elevando o crescimento de um país, e, à melhoria dos padrões de vida da população, buscando melhorar o quadro social dos indivíduos.

Outro ponto importante da entrevista, foi investigar se a empresa possui algum incentivo fiscal, tendo como reposta:

"Não temos incentivos fiscais pelo fato de sermos uma empresa de pequeno porte".

No Brasil os incentivos fiscais foram introduzidos em 1993 pela Lei $\mathrm{n}^{\circ}$ 8.661/93, que instituiu o Programa Tecnológico da Indústria e o Programa de Desenvolvimento Tecnológico 
de Agricultura, com tudo nem todas as industrias podem aderir, pois terão que está incluso em alguns critérios que levam em conta o regime tributário (ARAÚJO, 2017).

Os incentivos fiscais consistem em uma forma que o governo disponibiliza as indústrias para poderem investirem em seus negócios e poderem acrescentar um número maior de mão de obra, diminuindo os custos do seu produto (SILVA, 2017).

Segundo Bacha (2013) a crise econômica junto com a alta carca tributária tem sido uns dos fatores que acarretam o fechamento de muitas indústrias no Brasil, ou evasão para outros países que possam dar segurança governamental, e tributária para que essas empresas possam crescer, alinhado a isso o país tem perdido milhões de postos de trabalho.

Conforme a citação acima, foi possível corroborar a resposta oferecida pelo empresário entrevistado, que quando perguntado se os impostos sobre sua empresa têm prejudicando o seu crescimento o mesmo respondeu:

"Sim. Prejudica o desenvolvimento da minha empresa, uma vez que essa carga tributária faz com que haja um aumento no custo dos produtos".

A alta carga tributária brasileira impossibilita os investimentos no país, inibindo que as empresas brasileiras possam fornecer preços acessíveis para os seus produtos, com a atual globalização do mercado, tornando-se inviável a competitividade com os produtos e preços ofertados pelas empresas chinesas por exemplo (VEDANA, 2017).

Por último se questionou se a empresa suportaria um aumento na carga tributária, ao que o empresário investigado responde que:

"Não suportaria, ficaria dificil competir com outras empresas concorrentes".

Segundo Campagnolo (2011), a carga tributária hoje está em quase 40\% do Produto Interno Bruto do País e o brasileiro está no limite do que pode pagar em impostos, e ao contrário do que muitos pensam, todos são consumidores, quando é requerido um serviço, ou quando comprado algo, esses impostos são repassados para os consumidores na grande maioria.

No atual cenário brasileiro, além dos custos, a carga tributária, a falta de incentivos fiscais para as empresas de pequeno porte, essas empresas concorrem grandes fabricantes que por sinal tem incentivos por parte do governo.

Se no setor produtivo brasileiro houvesse um estimulo na aplicação da produção, um ambiente favorável para os negócios, atraísse novos investimentos, com preços mais acessíveis o seu potencial seria muito mais elevado, fazendo assim com que a grande evasão das empresas diminuísse (VEDANA, 2017). 


\section{Considerações Finais}

O presente estudo teve como objetivo investigar a relação existente entre a carga tributária e o desenvolvimento econômico de uma indústria de transformação, sendo desenvolvido junto ao empresário, que já está atuando no mercado a oito anos, e encontra-se localizada na cidade de Icó - Ceará, no Conjunto Gama.

Constatou-se que a alta carga tributária incidente sobre a empresa, tem sido um entrave no desenvolvimento econômico da mesma, tornando-se um crescimento lento, e dificultando a concorrência perante outras indústrias. A elevada carga tributária suportada pelos empresários brasileiros, mais precisamente, sobre o setor da indústria de transformação, faz com que muitos empresários se desloquem, ou prefiram sair do país, e mesmo havendo uma ajuda do planejamento tributário, não se consegue desenvolver e crescer de forma exponencial.

E no que se diz respeito a empresa em questão, que foi realizada a pesquisa, só fez com que constatasse as afirmações dos autores, onde a quantidade de impostos que são pagos pela empresa prejudica no seu desenvolvimento, e tendo esse aumento consequentemente prejudica mais ainda os lucros da empresa, tendo como agravante principal de que a empresa não suportaria esse aumento, uma vez que a empresa em questão não conseguiria competir com as concorrentes que já estão a mais tempo no mercado.

\section{Referências}

BRASIL. Decreto-lei $\mathrm{n}^{\circ}$ 195, de 24/02/1967. Diário Oficial - República Federativa do Brasil: Poder Legislativo. Brasília, DF, 1967. Disponível em: http://www.planalto.gov.br/ccivil_03/decreto-lei/del0195.htm, acesso: 10/09/2018.

Lei n. 9.718, 25/11/1998. Diário Oficial - República Federativa do Brasil: Poder Legislativo. Brasília, $\quad$ DF, $\quad 1998 .<\mathrm{http}: / /$ repositorio.ipea.gov.br/bitstream /11058/6761/1/Radar_n9_Incentivos.pdf/> acesso em: 08 de novembro de 2018

ARAUJO, B. C. Incentivos fiscais à pesquisa e desenvolvimento e custos de inovação no Brasil. 2017.

BACHA, E. Integrar para Crescer: O Brasil na Economia Mundial. Instituto de Estudos e Políticas Econômicas do Rio de Janeiro: 2013.

BORBA, Claudio. Direito Tributário. Rio de Janeiro: Forense; São Paulo: MÉTODO, 27. ed, 2015. 
BRASIL, FIESP. A carga tributária no Brasil repercussões na indústria de transformação. 2015. Disponível em: http://www.fiesp.com.br/indices-pesquisas-e-publicacoes/cargatributaria-no-brasil-repercussoes-na-industria-de-transformacao-2015/attachment/a-cargatributaria-no-brasil-2015/ > acesso em: 09 de novembro 2018

BRASIL, FIRJAN. A carca tributária para a indústria de transformação. 2016. Disponível em: <http://www.firjan.com.br/publicacoes/publicacoes-de-economia/a-carga-tributaria-paraa-industria-de-transformacao.htm/>Acesso em: 09 de novembro de 2018

BRASIL, Secretaria da Receita Federal. Documento de Arrecadação do Simples Nacional DAS. Disponível em: http://www8.receita.fazenda.gov.br/SimplesNacional /Documentos/Pagina.aspx?id=3, acesso em: 12/09/2018.

BRASIL, Secretaria da Receita Federal. Lei Complementar $n^{\circ} 123$, de 14 de Dezembro de 2006. Disponível em: http://www.receita.fazenda.gov.br/Legislacao/Leis Complementares/2006/leicp123.htm, acesso em: 12/09/2018.

BRASIL. Código Tributário Nacional. 2.ed, Brasília: Senado Federal, Subsecretaria de Edições Técnicas, 2012.

BRASIL. Decreto no 3.000, de 26 de março de 1999. Regulamenta a tributação, fiscalização, arrecadação e administração do Imposto sobre a Renda e Proventos de Qualquer Natureza. Brasília, 1999.

CAMPAGNOLO, Edson Luiz. A Sombra do Imposto. FIEP-PR, Curitiba: 2011.

FABRETTI, L. C. Incorporação, fusão, cisão e outros eventos societários: tratamento jurídico, tributário e contábil. São Paulo: Atlas, 2001.

FABRETTI, Láudio Camargo. Contabilidade Tributaria. 10. ed. São Paulo, Atlas, 2006.

GIL, A. C. Como elaborar projetos de pesquisa. 5. ed. São Paulo: Atlas, 2010.

GOMES, A. A. Estudo de caso-Planejamento e métodos. Nuances: estudos sobre Educação, v. 15, n. $16,2008$.

GOODE, W.J.; HATT, P. K. Métodos em pesquisa social. 5a ed. São Paulo: Companhia Editora Nacional, 1979.

HAGUETTE, T. M. Frota. Metodologias qualitativas na Sociologia. $5^{\text {a }}$ edição. Petrópolis: Vozes, 1997.

KALUME, L. R. V.; CORSEUIL, C. H. L.; SANTOS, D. D. O simples nacional e a formalização das firmas no Rio de Janeiro. 2013.

LANZANA, A. E. T. Economia Brasileira. 3a . ed. São Paulo: Atlas, 2009.

NEVES, S.; VICECONTI, P.E.V. Curso prático de imposto de renda: pessoa jurídica e tributos conexos, CSLL - PIS - COFINS. São Paulo: Frase, 2007. 
PEREIRA, L. C. B. Desenvolvimento Econômico e Revolução Capitalista. Escola de Economia de São Paulo: 2008

RICHATO, J. M. Lucro Presumido versus Simples Nacional: Análise de uma prestadora de serviços. Universidade Federal do Rio Grande do Sul - Porto Alegre, 2010.

SACHS, I. Desenvolvimento: includente, sustentável, sustentado. Rio de Janeiro: Garamond, p. 1.152 , 2004.

SANTOS, A. R.; OLIVEIRA, R. C. M. Planejamento Tributário com ênfase em empresas optantes pelo lucro real. Faculdade de Telêmaco Borba, FATEB-PR, 2008.

SEN, A. K. Desenvolvimento como liberdade. São Paulo: Companhia das Letras, p. 4092000.

SILVA, G. E. D. Arranjos produtivos locais e incentivos à exportação: uma análise das indústrias de calçados de São João Batista (SC). 2017

SILVA, J. M.; RODRIGUES, A. I. LALUR - Guia Prático de Escrituração do Livro de Apuração do Lucro Real. 4. ed. São Paulo, CENOFISCO, 2006.

VEDANA, G. A. Custo Brasil, gestão e desenvolvimento das indústrias de médio porte do Sudoeste do Paraná. Universidade Estadual do Oeste do Paraná: 2017.

Como citar este artigo (Formato ABNT):

CORREIRA, Clislânio da Silva; DIÓGENES, Daiana Ferreira de Alencar. A Análise da Carga Tributária na Atual Conjuntura Econômica Brasileira na Indústria de Transformação. Id on Line Rev.Mult. Psic., 2019, vol.13, n.43, p. 530-542. ISSN: 1981-1179.

Recebido: 21/11/2018;

Aceito: 26/11/2018 